http://jmscr.igmpublication.org/home/

ISSN (e)-2347-176x ISSN (p) 2455-0450

crossref DOI: https://dx.doi.org/10.18535/jmscr/v7i7.151

Journal Of Medical Science And Clinical Research

IGM Publication

An Official Publication of IGM Publication

\title{
A Case Series of Elective Splenectomy in Hemolytic Anemias - Our Experience at a Tertiary Care Hospital in North Coastal Andhra
}

\author{
Authors \\ Dr Buddha Kanaka Maha Lakhsmi ${ }^{1}$, Dr Vadisetti Satya Niharika ${ }^{2}$, \\ Dr Chinthagada Jaya Raj ${ }^{*}$, Dr Deevi Murali Manohar ${ }^{4}$, Dr Simhadri Uday Kiran ${ }^{5}$ \\ ${ }^{1}$ Assistant Professor of Surgery, ${ }^{2} 3^{\text {rd }}$ year post-graduate, \\ ${ }^{3}$ Professor and HOD of Surgery, ${ }^{4,5} 2^{\text {nd }}$ year post-graduate
}

Department of General Surgery, Andhra medical college, Visakhapatnam, Andhra Pradesh, India

*Corresponding Author

Dr Chinthagada Jaya Raj, MS.MCh.

Professor and HOD of Surgery, Department of General Surgery, Andhra Medical College, Visakhapatnam,

Andhra Pradesh, India Pin code - 530002

\begin{abstract}
Hereditary hemolytic anemias are disorders with a variety of causes, including red cell membrane defects, red blood cell enzyme disorders, congenital dyserythropoietic anemias, thalassemia syndromes, and hemoglobinopathies. Splenectomy is one possible therapeutic approach in management and haematological conditions were cited as one of the leading indications. However, the short-term and long-term advantages and challenges that splenectomy offers in the scenario of these anemias is not strongly evidence-based, except for that in hereditary spherocytosis as of now. Aims of our study are to establish the indication for elective splenectomy in adults with hemolytic anemias and to evaluate the effectiveness of splenectomy in treating the indication. We also review our experience in the management of such patients and compare with other studies. A case series of 27 patients over a period of two years from June 2016 to June 2018 referred to our department were included. According to our study, hypersplenism was the most common indication for splenectomy in adult patients with hemolytic anemias. We have followed open approach and performed simultaneous splenectomy and cholecystectomy for all patients with concomitant cholelithiasis. Our study achieved $100 \%$ improvement in the indication with minimal comorbidity due to strict adherence to protocols even in these patients. However, more detailed studies in this subset of patients is needed for establishment of guidelines and optimal outcomes.

Keywords: Spleen, hemolytic anemias, adult, hypersplenism, elective, splenectomy.
\end{abstract}

\section{Background}

Hereditary hemolytic anemias are disorders with a variety of causes, including red cell membrane defects, red blood cell enzyme disorders, congenital dyserythropoietic anemias, thalassemia syndromes, and hemoglobinopathies. ${ }^{[1]}$ Splenectomy is one possible therapeutic approach in management and haematological conditions were cited as one of the leading indications. ${ }^{[2]}$ However, the short-term and long-term advantages and challenges that splenectomy offers in the scenario of these anemias is not strongly evidence-based, except for that in hereditary spherocytosis as of now. 


\section{JMSCR VoI||07||Issue||07||Page 847-852||July}

\section{Aims and Objectives}

1. Establish the indication for elective splenectomy in adults with hemolytic anemias

2. Evaluate the effectiveness of splenectomy in treating the indication

3. Emphasize the importance of strict protocols to minimize complications

4. To review our experience in the management of patients with hematological disorders undergoing splenectomy and to compare with other studies.

\section{Methods}

A case series of 27 patients over a period of two years from June 2016 to June 2018 referred to the Department of Surgery at our institute. No exclusion criteria followed.

\section{Results}

In 27 patients with hemolytic anemia, elective splenectomy was performed without mortality and with minimal morbidity. Twenty -three patients with sickle cell disease and four with hereditary spherocytosis underwent surgery.

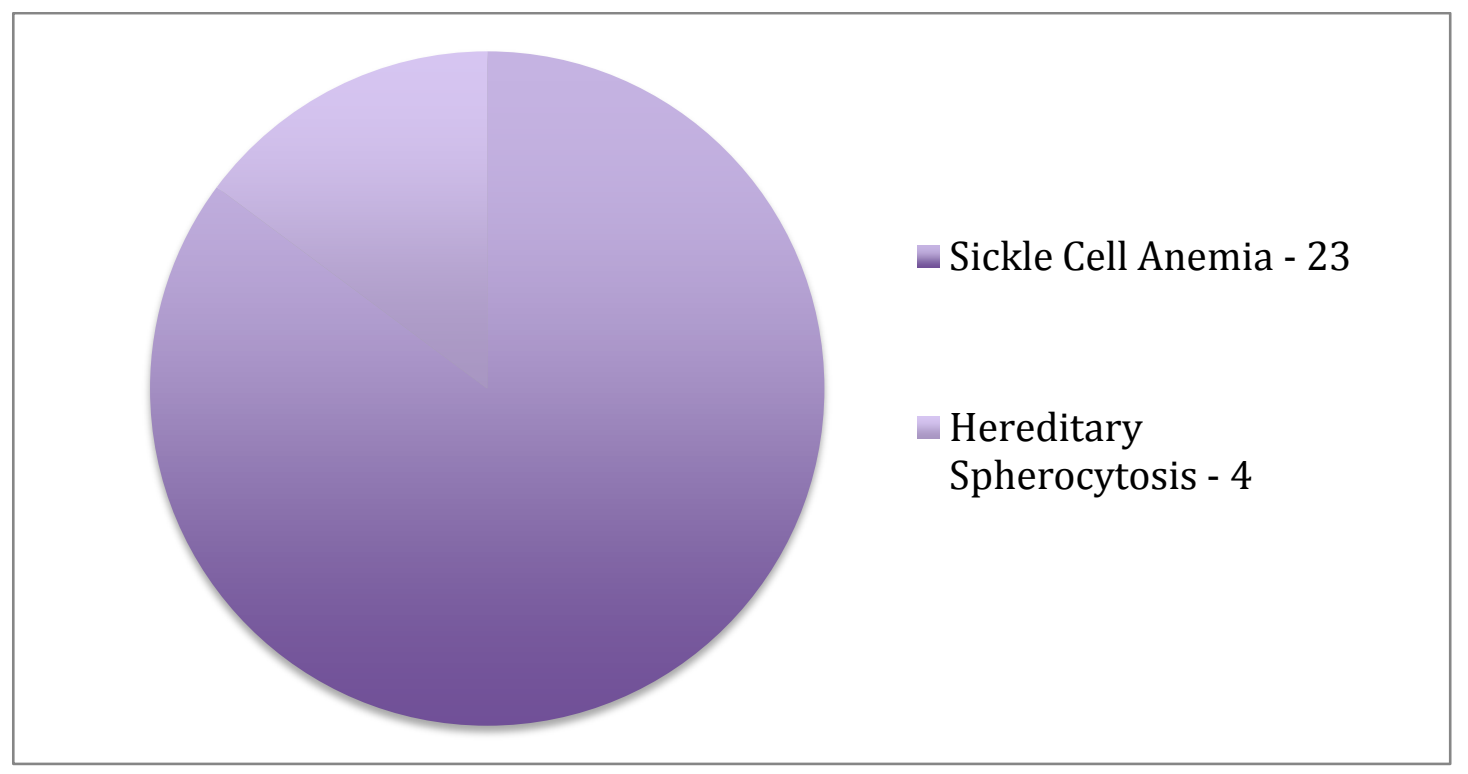

\begin{tabular}{|c|c|c|c|}
\hline Criteria & Mean values/Remarks & N. Machado et $\mathrm{al}^{[3]}$ & Al-Salem AH et al ${ }^{[4]}$ \\
\hline Age at splenectomy & $\begin{array}{l}18.6 \text { years }(\mathrm{HS}), \\
20 \text { yrs }(\mathrm{SCA})\end{array}$ & $\begin{array}{l}29.2(\mathrm{HS}) \\
6.25(\mathrm{SCA})\end{array}$ & 7.6(SCA) \\
\hline Sex & Female -8, Male - 19 & $\begin{array}{l}\text { Female-36, } \\
\text { Male-60 }\end{array}$ & $\begin{array}{l}\text { Female }-42, \\
\text { Male }-61\end{array}$ \\
\hline $\begin{array}{l}\mathrm{Hb} \\
\text { electrophoresis } \\
\text { (Normal in cases of } \\
\text { hereditary spherocytosis) }\end{array}$ & $\begin{array}{l}\mathrm{HbF}-22 \% \\
\mathrm{HbS}-75 \% \\
\mathrm{HbA}-\mathrm{absent} \\
\mathrm{HbA} 2-3 \%\end{array}$ & $\mathrm{HbF}-21.2 \%$ & $\mathrm{HbF}-20.2 \%$ \\
\hline Indication of splenectomy & $\begin{array}{l}\text { 1.Hypersplenism(18) }-78.2 \% \\
\text { 2.Dragging pain }(4)-17.3 \% \\
\text { 3.Splenic abscess }(1)-4.3 \% \\
\text { - Anemia in HS(4) }\end{array}$ & $\begin{array}{l}\text { 1.Splenic sequestration } \\
\text { 2.Hypersplenism }\end{array}$ & $\begin{array}{l}\text { 1.Splenic sequestration } \\
\text { 2.Hypersplenism }\end{array}$ \\
\hline $\begin{array}{l}\text { Pre-operative } \\
\text { investigations }\end{array}$ & $\begin{array}{l}\text { Anemia }-100 \% \\
\text { Mean } \mathrm{Hb}-7.6 \mathrm{gm} \% \\
\text { Leucopenia }-10 \% \\
\text { Mean TC }-5600 \text { cells } / \mathrm{mm} 3 \\
\text { Thrombocytopenia }-15 \% \\
\text { Mean Platelet count }-1.5 \text { lakhs } / \mathrm{mm} 3\end{array}$ & Mean $\mathrm{Hb}-6.35 \mathrm{gm} \%$ & Mean $\mathrm{Hb}-2.5 \mathrm{gm} \%$ \\
\hline
\end{tabular}




\section{JMSCR VoI||07||Issue||07||Page 847-852||July}

Pre-operative preparation

1) All patients received polyvalent pneumococcus, Haemophilus influenza type B, and Meningococcus vaccinations two weeks before elective surgery.

2) We did not give influenza vaccine.

3) Proper hydration with 4-5 liters of water from 10 days pre-operatively.

4) Two units of packed red cell transfusion two days before surgery to improve $\mathrm{Hb}$ level.
5) Exchange transfusion was done before surgery. Usually, one transfusion was sufficient and was dependent on the $\mathrm{HbS}$ fraction in electrophoresis and anemia.

All cases of splenectomy that had co-existent cholelithiasis, irrespective of symptoms underwent both splenectomy and cholecystectomy.

\begin{tabular}{|l|l|l|l|}
\hline Criteria & Remarks & N. Machado et al[3] & Al-Salem AH et al[4] \\
\hline Type of surgery & $\begin{array}{l}\text { Open approach(26)-96.2\% } \\
\text { Laparoscopic approach(1)-3.7\% }\end{array}$ & & \\
\hline Mean weight & 850 gms & 577 gms & \\
\hline Histology post-op day at & Congestive splenomegaly & & \\
\hline $\begin{array}{l}\text { Mean d.5 } \\
\text { discharge }\end{array}$ & & \\
\hline Cholecystectomy & 13 & & 28 \\
\hline Co-existent cholelithiasis & Sickle cell - 9, HS - 4 & HS - 6 & 28 \\
\hline Symptomatic cholelithiasis & Sickle cell - 5, HS - 3 & HS - 4 & 4 \\
\hline
\end{tabular}

\section{Peri-operative management protocols}

Particular protocols for an improved intraoperative and post-operative period were implemented.

1. Aggressive hydration with IV fluids @ $125 \mathrm{ml} / \mathrm{hr}$

2. Oxygen supplementation@2-4 liters/min for at least three days.

3. Avoid hypothermia and acidosis.

4. DVT prophylaxis with $20 \mathrm{mg}$ Clexane was given for five days postoperatively for high-risk patients.
5. Adequate pain control with epidural analgesia, tramadol and paracetamol. NSAIDS avoided.

6. Daily $\mathrm{CBC}$ monitoring for $\mathrm{Hb}$ and platelet counts. Transfused PRBC if necessary.

\section{Postoperative evaluation}

Average post-op haemoglobin - $10 \mathrm{gm} / \mathrm{dl}$.

Simultaneous resolution of leucopenia and low platelet count observed.

\begin{tabular}{|l|c|}
\hline Adverse events in the six weeks follow up period & Number of events \\
\hline Opportunistic Post-Splenectomy Infection (OPSI) & None \\
\hline Deep Venous Thrombosis & None \\
\hline Pulmonary Embolism & None \\
\hline Thrombocytosis & 2 \\
\hline Wound Infection & 4 \\
\hline Post-operative jaundice & 1 \\
\hline Pneumonia & None \\
\hline Death & (during 4 -7 days, relieved spontaneously) \\
\hline
\end{tabular}

Post-operative prolonged antibiotic prophylaxis was not given at our institute.
Haematology team was responsible for maintenance of long term follow-up and not included in this paper. 


\section{Discussion}

Hereditary hemolytic disorders are a group of diseases caused by a variety of mutations affecting different components of the red blood corpuscle; all with anemia as the common characteristic, and with a broad spectrum of clinical severity.

The understanding, investigation, and management of these diseases are mainly medical. However, particular complications may need surgical intervention and the data on experience with such conditions, and their appropriate management is still inadequate. Most of the studies found were reported from South American, African, and Middle Eastern countries and with the study population more commonly being pediatric. The burden of the adult population facing complications of these conditions has been reported to be low. However, the relative incidence of hemolytic disorders in our region and the frequent persistence of spleen above the average age for auto-splenectomyis responsible for our study.

The spleen is one of the largest lymphatic organs, which is the only one directly connected to the blood circulatory system and its morphology and function long remained unstudied. It makes an essential contribution to the cellular and humoral immune response, in addition to its phagocytic, catabolic and reservoir functions. The reason for surgery on spleen differs with the pathophysiology of the disease.

Hereditary Spherocytosis is an inherited disorder characterized by the presence of spherical-shaped RBCs on peripheral blood smears and is most commonly associated with autosomal dominant inheritance. RBC membrane proteins are abnormal in these patients and the defects in these membrane components increases fragility. The primary organ responsible for the destruction of RBC's with the defective membrane is the spleen, and hence, splenectomy improves anemia. BoltonMaggs et al. ${ }^{[5]}$ elucidated the indications for surgery in hereditary spherocytosis but the value of concomitant cholecystectomy for asymptomatic gallstones remained controversial. In our case series, cholecystectomy was done concomitantly for all cases irrespective of symptoms.

Sickle Cell Disease is caused by mutation in the $\beta$ globin gene resulting in the synthesis of abnormal hemoglobin, HbS. Cyclic polymerization or depolymerization of deoxy-HbS generates dense, dehydrated red cells that play a central role in the clinical manifestations of Sickle cell disease, in which intravascular sickling leads to vasoocclusion and impaired blood flow with ischemic reperfusion injury. Some organs are more vulnerable to damage from this injury due to their peculiar anatomic organization mainly characterized by sluggish circulation, low $\mathrm{pH}$ and local high pro-oxidant environment. The altered physiology makes them liable to develop splenic complications requiring splenectomy.

An acute splenic sequestration crisis, one of the most feared acute complications of sickle cell disease is defined as severe abdominal pain and distension associated with spleen enlargement, a decrease in hemoglobin level by at least $2 \mathrm{~g} / \mathrm{dL}$ and stable or high reticulocyte count compared to that of the patient in steady state. It is one of the most common indications for splenectomy in childhood for these patients as seen by various studies but it was not in our study as we included only adult patients. As it is done in an emergency for this indication, vaccination is performed within 2 weeks after splenectomy for all these patients as by Uranus et al. ${ }^{[6]}$ Our study consisted of only elective splenectomy and hence all patients were vaccinated pre-operatively.

Hypersplenism, defined as chronic splenic enlargement with lowered hemoglobin concentration and decreased platelet and leukocyte counts. It is the second major indication for splenectomy in Sickle cell patients in accordance with other studies. Surgery is usually done if there is hypersplenism, pressure effects of the spleen or failure to thrive. The transfusion is often ineffective in such patients because of red blood cell sequestration in the enlarged spleen.

Although splenectomy is the treatment for recurrent acute splenic sequestration crises and 
hypersplenism, there is no evidence that it increases hemoglobin level, decreases hemolysis, or improves patients' survival. In our series, the only indication was hypersplenism. This is in accordance with other studies from India like Rehmani et al., where hypersplenism was the commonest indication irrespective of the cause. ${ }^{[7]}$ Splenectomy may, however, increase thromboembolism.

An abdominal ultrasound should be done routinely preoperatively for all patients with SCA undergoing splenectomy, and if gallstones are discovered, they should undergo concomitant cholecystectomy. This is even so for asymptomatic gallstones. The addition of cholecystectomy to splenectomy does not increase the morbidity, but eliminates the subsequent complications of gallstones and simplifies their future management in case of abdominal crisis as the possibility of cholecystitis is eliminated.

The risk of overwhelming post-splenectomy infection (OPSI) is highest with encapsulated micro-organisms such as Streptococcus pneumoniae, Neisseria meningitides, and Haemophilus influenza. Asplenia is also a significant risk factor for severe infections with Plasmodium, Capnocytophaga canimorsus and C. cynodegmi (after an animal bite), Babesia spp. (after a tick bite), and Bordetella holmesii. The risk of post-splenectomy sepsis may vary according to the haemolytic condition (intermediate risk in spherocytosis and higher in other inherited anemias), patient's age at the time of surgery (highest before the age of 5 years) and time since the splenectomy was performed (risk highest during the first year after the intervention). However, the risk probably remains elevated for life.

Strategies to reduce the development of OPSI include: (i) patient's education, including advice to take urgent action in response to febrile episodes; (ii) vaccination and advent of new protein conjugate vaccines; (iii) prophylactic antimicrobial therapy; (iv) intra-operative normothermia; (v) early catheter removal; (vi) increased vigilance. ${ }^{[8,9]}$ Though these measures are thought to reduce the risk of OPSI greatly, studies reported inconsistency in implementation. ${ }^{[10]}$

It has been reported that, following splenectomy, there is an increased risk of early and late venous and arterial thrombosis, including acute splenic and portal vein thrombosis and delayed severe life-long complications.

Acute Spleno-Portal Venous Thrombosis after splenectomy is an early and life-threatening complication, which can lead to bowel ischemia and portal hypertension. This complication has been related to stasis in the splenic vein remnant. Large spleen size has also been identified as a risk factor for the development of SPVT; the surgical approach does not seem to affect the incidence of SPVT. Screening for thrombophilia has not been shown to allow early identification of patients at risk of SPVT after splenectomy.

It is remarkable that the rate for death from elective splenectomy in a large study is $1.6 \%$, making it a procedure of comparable risk compared to $1-2 \%$ mortality in pancreatectomy or hepatectomy series in high-volume centers. ${ }^{[11]}$ However, there was no mortality in our study. The less number of patients included in our study might be the reason for this.

Few studies have reported differences in the success of surgery, depending on the indication. ${ }^{[12]}$ There is a need for conduction of more studies in this topic with a specific focus on decision making for surgery and peri-operative protocols. In our study, all the signs have shown improvement in the early post-operative period.

\section{Conclusion}

For hemolytic conditions other than congenital spherocytosis, in which splenectomy is of uniform value, a decision to remove the spleen must be weighed on the severity of the hemolysis, the potential for achieving significant improvement in anemia and associated cytopenias, increased burden of blood transfusions against the risk of complications. 
Funding: None

Conflict of interest: None declared

Ethical approval: As it was a retrospective study, ethics clearance is not required

\section{References}

1. Iolascon A, Andolfo I, Barcellini W, et al. Recommendations regarding splenectomy in hereditary hemolytic anemias. Haematologica. 2017;102(8):1304-1313. doi:10.3324/haematol.2016.161166

2. Fellows IW, Hart S, Toghill PJ.Trends in splenectomy in the Trent region 1972-85. Postgrad Med J. 1988;64(750):267-70.

3. Machado NO, Grant CS, Alkindi S, Daar S, Al-Kindy N, Al Lamki Z, et al. Splenectomy for haematological disorders: a single center study in 150 patients from Oman. Int J Surg. 2009; 7:476-81.

4. Ahmed H. Al-Salem, "Splenic Complications of Sickle Cell Anemia and the Role of Splenectomy," ISRN Hematology, vol. 2011, Article ID 864257, $7 \quad$ pages, 2011. https://doi.org/10.5402/2011/864257.

5. Bolton-Maggs PH, Langer JC, Iolascon A, Tittensor P, King MJ General Haematology Task Force of the British Committee for Standards in Haematology. Guidelines for the diagnosis and management of hereditary spherocytosis2011 update.Br J Haematol. 2012;156:3749.

6. Uranüs S, Sill $H$. Splenectomy for hematological disorders. In: Holzheimer RG, Mannick JA, editors. Surgical Treatment: Evidence-Based and ProblemOriented. Munich: Zuckschwerdt; 2001. Available from: https://www.ncbi.nlm.nih.gov/books/NBK 6913/
7. Rehmani B, Kumar N, Pathak P. Changing trends in elective splenectomy at a tertiary hospital in North India: a 10 year study. IntSurg J 2017;4:2589-93.

8. Berenguer CM, Ochsner MG Jr, Lord SA, Senkowski CK. Improving surgical site infections: using National Surgical Quality Improvement Program data to institute Surgical Care Improvement Project protocols in improving surgical outcomes. J Am CollSurg. 2010;210(5):737-743.

9. Owen RM, Perez SD, Bornstein WA, Sweeney JF. Impact of Surgical Care Improvement Project Inf-9 on postoperative urinary tract infections: do exemptions interfere with quality patient care? Arch Surg. 2012;147(10):946-953.

10. Rodeghiero F, Ruggeri M. Short- and long-term risks of splenectomy for benign haematological disorders: should we revisit the indications? $\mathrm{Br} \mathrm{J}$ Haematol. 2012;158(1):16-29.

11. Bagrodia N, Button AM, Spanheimer PM, Belding-Schmitt ME, Rosenstein LJ, Mezhir JJ. Morbidity and Mortality Following Elective Splenectomy for Benign and Malignant Hematologic Conditions: Analysis of the American College of Surgeons National Surgical Quality Improvement Program Data. JAMA Surg.2014;149(10):1022-1029. doi:10.1001/jamasurg.2014.285

12. Bickenbach, K. A., Gonen, M., Labow, D. M., Strong, V., Heaney, M. L., Zelenetz, A. D. and Coit, D. G. (2013), Indications for and efficacy of splenectomy for haematological disorders. Br J Surg, 100: 794-800. doi:10.1002/bjs.9067. 